\title{
FORMAÇÃO CONTINUADA DE PROFESSORES DO CAMPO NO PROGRAMA ESCOLA DA TERRA E A CONCEPÇÃO DO CURRÍCULO
}

\author{
Norma Cristina Vieira ${ }^{1}$ \\ Rogerio Andrade Maciel $^{2}$ \\ Wanessa Rafaela Andrade Maciel $^{3}$
}

\section{INTRODUÇÃO}

Não podemos desconsiderar que a discussão sobre a formação de professores do campo é um projeto social em disputa, porque está constituído por uma sociedade capitalista que visa uma formação para o mercado de trabalho, de uma lógica da eficiência produtiva do agronegócio, um sistema globalizado e moderno, que critica, em boa medida, a forma de viver e a produção camponesa.

Como a educação não se concentra numa política sem ideologia, a formação de professores do campo também faz parte deste projeto de sociedade em disputa, porque valoriza a luta de classes nas relações sociais do camponês, em suas histórias de vida, seus saberes, seus fazeres e práticas produtivas com o campo (ARROYO, 2011).

A formação continuada dos professores do campo no Programa Escola da Terra constitui-se em fortalecer o desenvolvimento de propostas pedagógicas e metodologias adequadas às comunidades atendidas, no sentido de elevar o desempenho escolar dos estudantes dos anos iniciais do Ensino Fundamental que compõem suas turmas de multissérie (BRASIL, 2012).

As classes multisseriadas nos permitem entender a necessidade da construção de um olhar próprio acerca da educação pensada nas escolas do campo e, em especial das escolas multisseriadas

\footnotetext{
1 Professora Adjunta da Faculdade de Educação Universidade Federal do Pará- Campus de Bragança. E-mail: normacosta@ufpa.br

2 Professor Assistente da Faculdade de Educação. Universidade Federal do Pará- Campus Universitário de Bragança. Doutorando em Educação pela Universidade Federal do Pará-Campus Belém. E-mail: dancerogerio@yahoo.com.br

${ }^{3}$ Pedagoga pela Faculdade de Educação -Universidade Federal do Pará- Campus de Bragança. Participante do grupo de pesquisa em educação e meio ambiente e do grupo de Estudos Socio Ambiental Costeiro/ESAC. E-mail: wanwanessa maciel10@yahoo.com.br
} 
na Amazônia, vinculadas à diversidade de populações que vivem no meio rural, considerando seus diferentes e conflitantes modos de vida e de organização do trabalho, tradições, histórias, condições socioeconômicas e culturais (ROCHA; HAGE, 2010).

O termo multissérie é identificado por uma justa-posição que se estabelece por dois termos: multi e seriado. São duas conotações que expressam um olhar quantitativo em frente às várias séries presentes em uma única sala de aula, o que fragmenta a operacionalização oficial do sistema de série ou ciclos de aprendizagem, hierarquizados historicamente pela seleção de conteúdos que são distribuídos nas séries ou ciclos (OLIVEIRA; FRANÇA; SANTOS, 2011).

O Programa Escola da Terra constitui-se através daformação continuadados docentes sobre a concepção dos diferentes territórios emersos em saberes e práticas cotidianas dos sujeitos.Os formadores problematizam estas realidades que servem de base para a construção do currículo crítico e emancipatório dos educadores e educandos, a partir de suas identidades agropesqueira, da agricultura e outras práticas socioculturais.

Pensar um currículo para escola do campo é inserir os conhecimentos da cultura e dos saberes cotidianos dos sujeitos (ARROYO, 2011). Os sujeitos do campo precisam ter acesso à educação de qualidade e isso perpassa pela inclusão de um currículo provindos dos saberes na religião, na história, na prática do trabalho do sujeito. Daí os saberes locais da população do campo são a base dos saberes culturais que permitem dialogar com o currículo das escolas do campo.

$\mathrm{O}$ artigo que segue apresenta resultados da pesquisa desenvolvida com professores do campo, em formação continuada desde 2013 pelo Programa Escola da Terra no Município de Bragança, localizado na Amazônia Oriental, à 220 km de Belém, capital do estado.

Do total de 131 Escolas de Ensino Fundamental da rede municipal de Bragança 83,2\% estão localizadas em áreas do campo, com destaque para as áreas indígenas, costeiras, ribeirinhas e agrícolas que caracterizam-se por uma grande diversidade ambiental e de atividades, sobretudo extrativistas. Há 136 professores de multissérie e dez tutores do município de Bragança cadastrados no Programa Escola da Terra (BRASIL, 2016).

Para a obtenção dos resultados foi desenvolvida a observação in lócus comparticipação em várias atividades realizadas nas formações. Entrevistas semiestruturadas com dez participantes do programa (3 professores em formação, 3 tutores, 1 coordenador estadual, 1 Coordenador Municipal pedagógico, 2 Coordenadoras da Secretaria Municipal de educação) e grupo focal, também foram utilizados na coleta de dados. A escolha dos participantes contou com várias estratégias, 
destacando-se a participação nas atividades do Programa Escola da Terra desde a sua implantação no município, ano de 2013.

\section{DIÁLOGOS SOBRE A FORMAÇÃO CONTINUADA DOS PROFESSORES NO PROGRAMA ESCOLA DA TERRA E A CONCEPÇÃO DO CURRÍCULO CONTEXTUALIZADO}

A importância de considerar a formação de professores do campo no Programa Escola da Terra não pode ser analisada sem a compreensão de alguns determinantes: sua implantação, função dos participantes e a concepção sobre o programa. É notório considerar, ainda, que estes determinantes possibilitam identificar os princípios educativos freireanos e a proposição do currículo crítico, neste programa de formação de educadores.

\section{A implantação do Programa Escola da Terra: do global ao local}

A escola da terra é um programa do governo federal quecompõe uma das ações do Programa Nacional do Campo- PRONACAMPO. Este foi instituído em 20 de março de 2012, por meio da portaria 86 de 02 de fevereiro de 2013. O PRONACAMPO, obtém ações específicas designados para à efetivação do direito à educação dos povos do campo e quilombola, considerando as reivindicações históricas oriundas dessas populações (BRASIL,2012).

O PRONACAMPO constitui-se em política de educação específica para o campo. Daío Ministério da Educação tem como atribuição, juntamente com os sistemas públicos de ensino e os movimentos sociais e sindicais do campo, desenvolver a efetivação de suas ações para e com o campo, cumprindo os marcos legais da LDB 9394/96, que compreende a educação como um direito público e subjetivo e reconhece a enorme dívida do poder público em relação ao direito dos povos do campo à educação (BRASIL, 2012).

A portaria 579, de 02 de Julho de 2013, se constitui pela implantação do Programa Escola da Terra. É importante mencionar isto, porque nem todos os Estados Brasileiros e seus respectivos municípios aderiram ao Programa Escola da Terra. De um total de 26 Estados Brasileiros e um distrito federal, o programa escola da terra atua em 14 estadosBrasileiros.

A seguir demonstra-se na imagemabaixo, os respectivos estados que desenvolve ações com o programa escola da terra: 


\section{Imagem 01: Composição do programa escola da terra em alguns estados brasileiros}

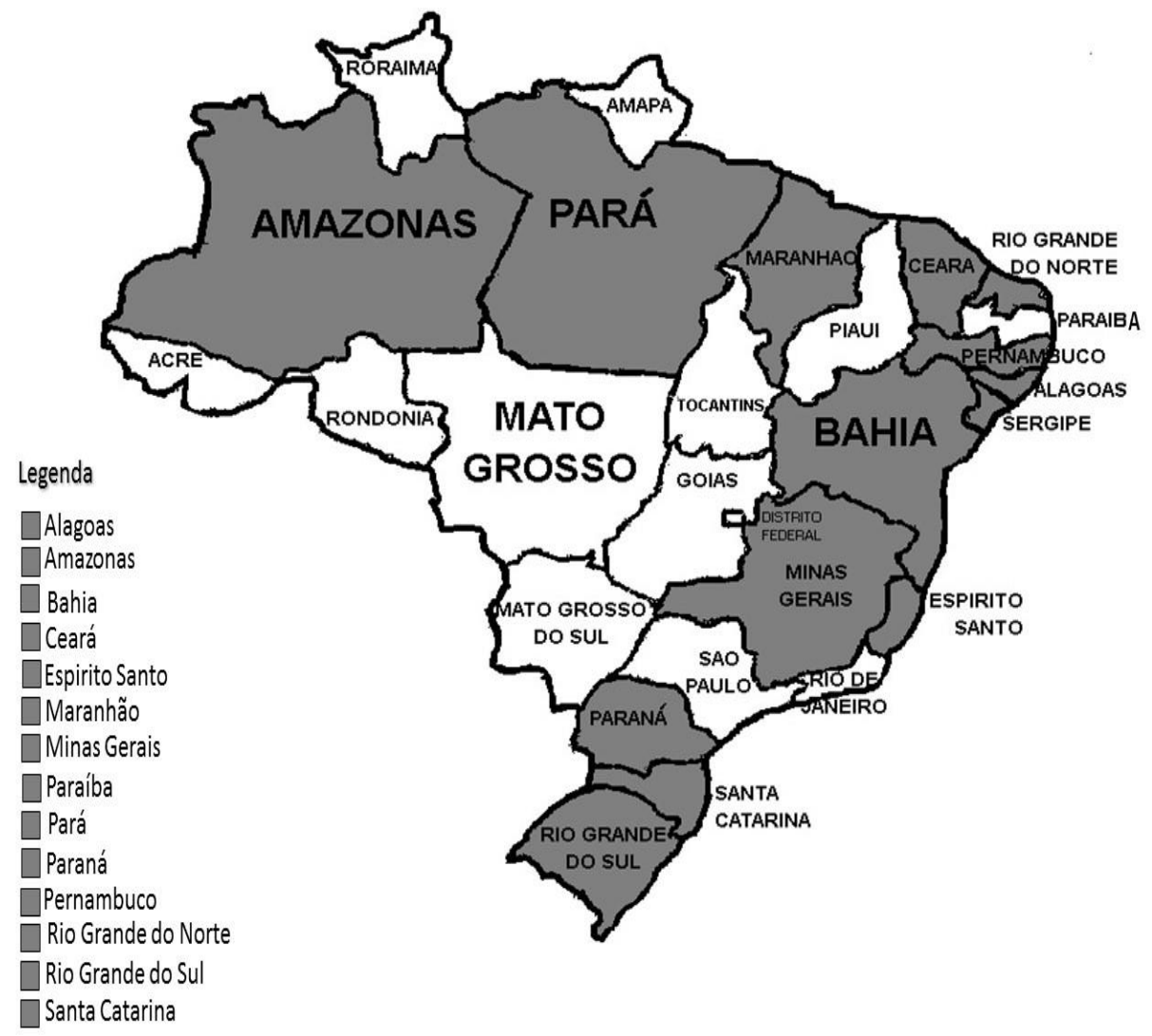

Fonte: Acervo pessoal. Agosto, 2016

Neste mapa e de acordo coma legenda destacado em cinza, encontram-se os 14 Estados brasileiros e o distrito federal que desenvolvem a formação continuada do Programa Escola da Terra. NoEstado do Pará de144 municípios,09aderiram ao Programa (Imagem 2). 


\section{Imagem 02:A presença do Programa Escola da Terra nos municípios do Estado do Pará}

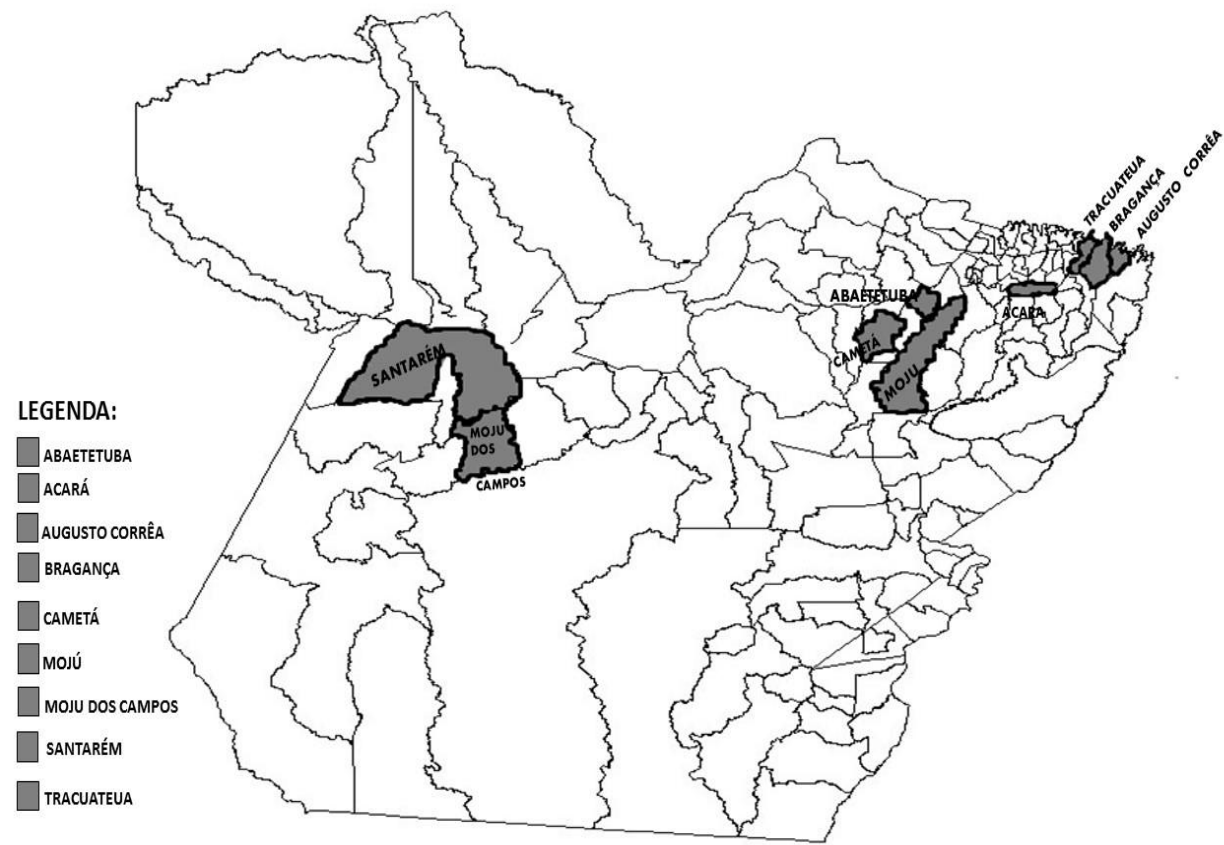

Fonte: Acervo pessoal,agosto 2016.

No Estado do Pará o curso de formação continuada atende os professores dos municípios de Abaetetuba, Acará, Augusto Corrêa, Bragança, Cametá, Moju,Mojuídos Campos, Santarém e Tracuateua. Para Hage (2014)o universo de docentes que trabalham em escolas multisseriadas e quilombolas no Pará aproxima-se a uma quantidade de dez mil educadores que atuam nos 144 municípios e, por isto estes docentes necessitam de formação continuada para melhorar suas práticas no cotidiano escolar.

No Município de Bragança, lócus deste artigo, 105 comunidades em que as turmas de multissérie estão inseridasparticipam do Programa Escola da Terra (Imagem 3): 


\section{Imagem 03: Identificação das comunidades que participam do Programa Escola da Terra}

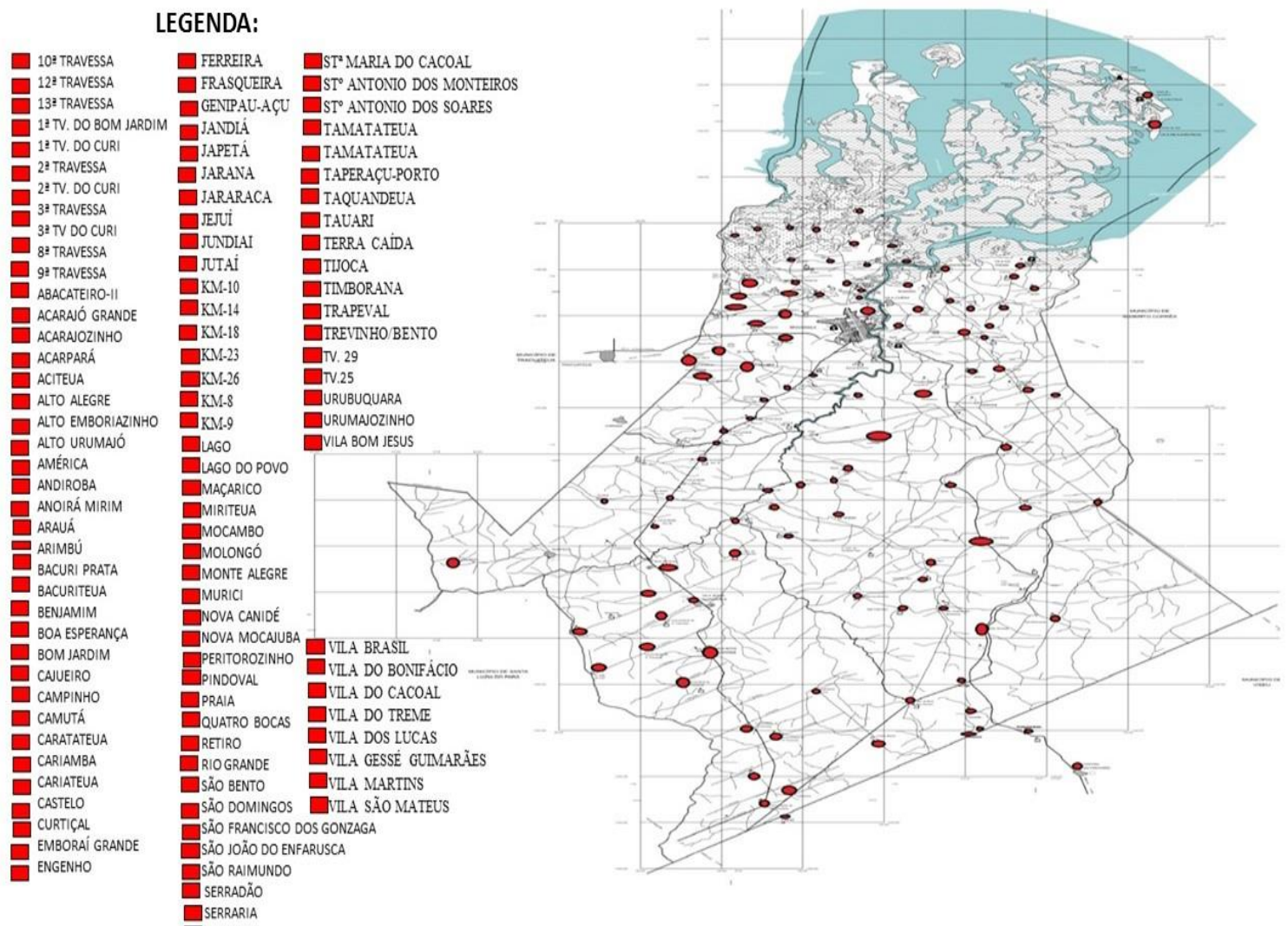

Fonte: Acervo Pessoal. Agosto, 2016.

É preciso considerar que essas 105 comunidades representam um número significativo de comunidades e escolas envolvidas neste processo educativo.

Diante destas relações entre Estados e Municípios que o Programa Escola da Terra atua, o município de Bragança efetuou sua adesão em 2013, conforme depoimento abaixo:

Desde o início de janeiro de dois mil e treze, foi quando a gente começou o processo de adesão. Desde lá a gente permaneceu organizando, aí em treze de julho de 2013, foi aprovado a adesão, daí começa a organização dos sujeitos no programa (Coordenadoras da educação do campo e tutoras do Programa Escola da Terra, 2016).

Observa-se na fala das coordenadoras que o Programa Escola da Terra foi implantado desde de 2103 na Secretaria Municipal de Bragança. E, após sua implantação aconteceu a organização dos participantes, coordenadorese tutores, para o processo de formações dos professores cursistas. 
Os coordenadores que compõe o Programa Escola da Terra estão constituídos numa esfera estadual e municipal. Esta organização, aliada a experiência dos formadores definiu a escolha dos coordenadores no Programa Escola da Terra no Estado do Pará.

Existe uma coordenação de formação, formada por professores da universidade que já tinha experiências com a educação do campo e que vinha de outros programas saberes da terra e do PRONERA, então S.M já trabalhou com o PRONERA, a S.P.já trabalhou com saberes da terra, eu já trabalhei com o PRONERA e saberes da terra, então uma equipe de formadores que tem uma vasta experiência com educação do campo (Coordenador da Formação do programa escola da terra e Coordenador do Programa, 2016).

Identifica-se na fala do Coordenador, em entrevista, que os formadores do Programa Escola da Terra foram selecionados por terem uma vasta experiência com outros programas: o programa nacional de educação na reforma agrária- PRONERA e o Programa Saberes da Terra.Estes programas de alfabetização e escolarização de jovens e adultos também são instituídos pelo governo federal e são destinados a população do campo. Em Bragança a constituição se deu da seguinte forma:

Eu, S.M.H, sou o coordenador estadual. O professor E.M é o nosso coordenador da formação. Ele é coordenador dos formadores e acompanha o programa no Município de Bragança, por ter uma proximidade durantes os anos de 2013 e 2014 com a Secretaria Municipal de Educação de Bragança, o mesmo era o assessor da proposta pedagógico da SEMED (Coordenador Estadual do Programa Escola da Terra, 2016).

A existência de um coordenador estadual e um coordenador municipal que construiu a proposta pedagógica na Secretaria Municipal de Educação nos anos de 2013 e 2014 é um diferencial, porque ambos são conhecedores do perfil de educadores do município e suas realidades, facilitando a construção coletiva da proposta de formação para os educadores do campo. Além disto, há uma coordenação da instituição formadora que designa os professores formadores e o tutores a participarem das propostas pedagógicas de formação.

Sobre a função dos tutores nos municípios de sua abrangência, eles mensalmente, após os seus acompanhamentos nas comunidades, elaboram os relatórios da sua área de abrangência que serão homologados pelo Gestor Nacional, de acordo com calendário previamente estabelecido pela equipe do programa.Os relatórios mensais sistematizados dos tutores (assessores pedagógicos) da rede municipal e estadual, devem ter uma cópia arquivada e, comunicar oficialmente e sem demora a SECADI/MEC e a IPES responsável pelo curso de formação continuada da Escola da Terra sobre qualquer irregularidade que venha a ocorrer (BRASIL, 2012).

Neste sentido acredita-se que é de suma importância destacar as informações do Programa Escola da Terra do global ao local,porque isto permitiu identificar sua implantação, sua organização 
e a função dos participantes, possibilitando entender o processo de formação continuada de professores do campo e a proposição do currículo neste Programa.

\section{Formação continuada de professores no Programa Escola da Terra e os indicativos curriculares deste programa de formação.}

A formação continuada no Programa Escola da Terra, está constituída pelos princípios educativosfreireanos,para professores com as classes multisseriadas no campo. Isto nos permite analisar a formação continuada e a presença do currículo contextualizado nesta experiência educativa.

O Programa Escola da Terra nos permite considerar que há uma formação no campo teóricoreflexivo e a posteriori uma ação docente a partir deste campo reflexivo que foram tecidas durante as formações de educadores. A formação de educadores, apresenta um reconhecimento sobre o território de Bragança que está imerso na identificação dos seus rios, da sua comunidade que é dinâmica pelo trabalho da pesca, da agricultura familiar, da identidade cultural dos sujeitos.

No município de Bragança o curso de formação para os educadores, foram constituídos da seguinte maneira:

Quadro 01: Identificação das formações no programa escola da terra em Bragança-PA.

\begin{tabular}{|c|c|c|}
\hline \multicolumn{2}{|c|}{$\begin{array}{c}\text { PERÍODO DE } \\
\text { FORMAÇÃO }\end{array}$} & PROPOSTAS DE FORMAÇÃO \\
\hline a & 7 e 8/de abril 2014 & $\begin{array}{c}\text { História de Vida e Formação } \\
\text { Atividade: Árvore do Conhecimento }\end{array}$ \\
\hline a & 2 e 3/de maio 2014 & $\begin{array}{c}\text { O Campo da Educação do Campo e a Escola } \\
\text { no Campo das Contradições e Conflitos no Brasil e } \\
\text { Amazônia. }\end{array}$ \\
\hline a & $\begin{array}{c}16 \text { e } 17 / \text { de outubro } \\
2014\end{array}$ & $\begin{array}{c}\text { Identidade Cultural, História Local e } \\
\text { Território dos Povos do Campo Bragantino. } \\
\text { Patrimônio Cultural Material e Imaterial dos } \\
\text { Povos do Campo Bragantino. }\end{array}$ \\
\hline a & $\begin{array}{c}\text { Currículo, Ciências e Identidade } \\
\text { sociocultural. }\end{array}$ \\
\hline a 2014 & $\begin{array}{c}\text { Linguagem Matemática e a Representação } \\
\text { da realidade. }\end{array}$ \\
\hline
\end{tabular}




\begin{tabular}{|c|c|c|}
\hline a & $\begin{array}{c}28 \text { e } 29 \text { de abril de } \\
2016\end{array}$ & $\begin{array}{c}\text { Conhecimento Empírico x Conhecimento } \\
\text { Científico }\end{array}$ \\
\hline a & $\begin{array}{c}30 \text { de junho e 01 de } \\
\text { julho de } 2016\end{array}$ & $\begin{array}{c}\text { Feira de Partilha de Saberes e Fazeres das } \\
\text { Escolas multissérie das Escolas do Campo }\end{array}$ \\
\hline
\end{tabular}

\section{Fonte: Documento concedido pela coordenação da educação do campo, Bragança-PA 2016}

Conforme a exposição deste quadro acima, o curso de formação continuada dos educadores aconteceu em 03 anos, com um total de 07 formações.

No ano de 2014 foram realizadas 04 formações num intervalo de tempo de 01 a 02 meses. Em 2015 não houveformação para os educadores pela ausência de recurso financeiro. Em 2016, ocorreram 03 formações entre 01 a 02 meses, incluindo a partilha de saberes e fazeres da escola do campo.

Aprimeira formação em 2014foi pautada na história de vida dos sujeitos, da compreensão de educação do campo, dos patrimônios materiais e imateriais. Esta formação estava constituída na identidade dos sujeitos do campo e seus territórios.

Em 2016, a base da formação no Programa provocou o debate direcionando ao conhecimento científico versus o conhecimento empírico ${ }^{5}$, possibilitando enxergar os saberes e práticas dos educadores e educandos do campo, aqueles sujeitos que estão invisibilizados pela sociedade capitalista, homogênea e excludente, criando hierarquias e legitimando uma única forma de conhecimento.

Vale considerar que a última formação ocorreu com um momento de socialização dos saberes e fazeres dos educandos. Aqui a formação possibilitou trazer à tona os significados dos professores cursistas durante o processo das sete formações constituídas no Programa Escola da Terra.

A formação continuada de profissionais da Escola da Terra constitui-se em fortalecer o desenvolvimento de propostas pedagógicas e metodologias adequadas às comunidades atendidas, no sentido de elevar o desempenho escolar dos estudantes dos anos iniciais do ensino fundamental

\footnotetext{
${ }^{4}$ É a informação e o saber que parte do princípio das análises dos fatos reais e cientificamente comprovados.

${ }^{5}$ Conhecimento adquirido através da observação, da experiência, do senso comum, dispensando a necessidade de comprovação científica. Baseia-se na experiência cotidiana e é repassado de geração-a-geração.
} 
que compõem suas turmas, inclusiveno município de Bragança,nos territórios costeiros, agrícolas, estuarinos, ribeirinhos (BRASIL, 2012). Este programa consiste:

\begin{abstract}
$\mathrm{Na}$ formação continuada que visa colaborar com os professores das escolas rurais pra que organizem processos de formação das crianças pautadas pelo princípio do currículo contextualizado, formação integral, a realidade como objeto de estudo, a pesquisa como prática educativa, ao educando como sujeito do conhecimento, as comunidades como sujeitos de conhecimento, a organização do ensino de maneira interdisciplinar ,orientado pelo processo de formação a partir de tema geradores, complexos temáticos (Coordenador da Formação do Programa Escola da Terra e Coordenador do Programa, 2016).
\end{abstract}

De posse desta fala a formação continuada dos professores do campo no Programa Escola da Terra, tem como proposta contribuir com a prática pedagógica dos professores que atuam na multissérie. E, isto pode ser visualizado com os princípios da educação do campo, do currículo contextualizado, do respeito pela identidade cultural dos sujeitos que vivem no campo, da sua história, memória, territorialidade e patrimônio, princípios que empoderam a formação de educadores e das crianças como uma ação político, social e cultural dos povos do campo, inclusive no município de Bragança, Pará.

A preocupação inicial com a formação de educadores, sempre foi o professor e o aluno enquanto protagonistas de suas ações no chão da escola. Esta relação iniciava-se com a reflexão sobre o levantamentoda realidade como objeto de estudo, que se fez presente no princípio educativo da pesquisa sócio antropológica delineada por Freire (2011), que menciona a pesquisa como o levantamento das questões emergenciais nas instituições educativas, nas relações com as práticas sócio - culturais das comunidades, bem como nas relações entre a escola e movimentos sociais e socioeducativos, isto permite ao educador desnaturalizar o que ele ainda não conhece ou precisa ser conhecido.

Freire (1987), nos diz que a indagação de si e do contexto em que objeto de estudo nos leva a pesquisa e conhecer o que ainda não se conhece e precisa ser desvelado. Esta relação de ensino e pesquisa, propicia as diferentes dimensões que caracterizam a diferença da prática num movimento permanente de observação (curiosidade), e indagação sobre o conhecimento ou levantamento da realidade e sua transformação social.

O princípio educativo da pesquisa permite o levantamento da realidade das escolas que identifica o perfil de educandos que compõe as turmas de classes multisseriadas. Isto foi fundamental neste programa de formação que instigou aos educadores pesquisarem nos diferentes territórios onde estão situadas as escolas do campo. 
Freire (2011) salienta que o professor atuante na comunidade precisa ser respeitado, pois é ele que faz um processo de construção de conhecimento sobre a realidade local. Falamos isto, porque é na compreensão da realidade que se desvela os processos de alienação dos sujeitos.

O Programa Escola da Terra em Bragança, segue, em boa medida, as diretrizes de uma educação do campo, comoum espaço de formação continuada que privilegia as vivências, cultura, valores, identidades das crianças e adolescentes. Não para fechar-lhes horizontes, mas para abri-los ao mundo desde o campo, ou desde o chão que pisam. Por isto, há uma necessidade de considerar as vivências dos professores cursistas e dos alunos, e, isto é a base da organização do curso deformaçãoadotada pelo Programa Escola da Terra.

Cada programa educativo desenvolvido pelo governo federal no âmbito da formação de educadores tem uma organização a ser operacionalizada nas suas propostas pedagógicas. No que se refere ao Programa Escola da Terra este possui o compromisso com a execução da formação, seu acompanhamento e produção de documentos que se desdobram num tempo mediado pela carga horária.

A implementação da formação continuada dos educadores deveestaramparadocom a oferta de curso de formação, com uma carga horária total mínima de 180 horas, organizadas em períodos formativos, denominados:

Tempo-universidade que se constitui em encontros presenciais executados pelas instituições formadoras, com exigência de frequência ao curso, ministrado em carga horária entre 90 a 120 horas. Tempo escola-comunidade que são períodos formativos, realizados em serviço e acompanhados pelos tutores, com carga horária entre 60 e 90 horas. A soma da carga horária dos dois períodos formativos deve totalizar, no mínimo, 180 horas (BRASIL, 2012. P. 04).

A formação prevista numa lógica de tempo escolae tempo comunidade nos indica que há uma organização de divisão de carga horária para todos os participantes do Programa Escola da Terra.

Esta lógica de pensar uma formação no tempo escola e tempo comunidade, faz parte de uma concepção de educação atrelada a Pedagogia da Alternância, que possibilita aos professores do campo estudar e ter acesso ao conhecimento, não apenas como algo dado por outrem, mas como um conhecimento conquistado, construído a partir da problematização de sua realidade. Problematização essa que transita pela pesquisa e pelo olhar distanciado do pesquisador sobre o seu cotidiano, mas que interfere nas ações das crianças, dos jovens e dos adultos, quando atuam na mesma realidade (CORDEIRO; 2015). 


\begin{abstract}
A pedagogia em regime de alternância, compreende um período de frequência presencial no polo da universidade (tempo-escola) e outro de atividades realizadas em serviço (tempo-comunidade). Este, com acompanhamento de tutores. No modelo de formação da universidade estão previstos em encontros que são contabilizados pelacarga horária dos participantes (Coordenador estadual do Programa Escola da Terra, 2016).
\end{abstract}

Nesta afirmativa a pedagogia da alternância vem sendo definida como um processo contínuo de aprendizagem e formação na descontinuidade de atividades e na sucessão integrada de espaços e tempos. A formação está para além do espaço escolar e portanto, a experiência se torna um lugar com estatuto de aprendizagem e produção de saberes, em que o sujeito conquista um lugar de ator protagonista, apropriando-se individualmente do seu processo de formação (CORDEIRO,2015).

O Programa Escola da Terra de Bragança segue o modelode regime de alternância pelo tempo escola e tempo comunidade ${ }^{6}$. No tempo escola os professores cursistas recebem a formação pelos professores formadores da Universidade Federal do Pará. Ao retornarem para as escolas do campo que atuam os professores cursistas desenvolvem suas práticas pedagógicas, isto é possível ser desenvolvido porque está amparado pelo tempo comunidade, orientado pelo manual de gestão do referido Programa, possibilitando assim a execução da pesquisa sócio antropológica, a problematização da realidade e a identidade cultural dos sujeitos que compõem os territórios do Município de Bragança-PA.

Nessa lógica, Freire (1981) nos diz que a identidade cultural dos professores e dos alunos fazem parte da dimensão individual e de classe social dos sujeitos, cujo respeito se faz pela prática progressista e que não pode ser negado o assumir de nós por nós mesmos, ou seja, é preciso que tanto o educador quanto o educando se assumam enquanto sujeitos históricos e sociais, sem jamais perder de vistas as condições materiais do projeto neoliberal na sociedade capitalista. Para que aconteça este assumir-se de ambos, é preciso valorizar e respeitar a experiência histórica, política, cultural e social dos educadores e educandos, que ao se sentirem visibilizados neste processo acabam por refletir e agir sobre o movimento de luta, resistência e na busca de direitos que possibilitam exercer sua cidadania, a partir da apreensão da realidade.

A herança cultural das escolas de Bragança devem ser respeitadas e não petrificada, pois o olhar sobre as mudanças nas escolas e em seus territórios alteram formas de ser e pensar, e isto o educador desvela nas relações que se estabelecem nas comunidades com os sujeitos da educação,

${ }^{6}$ O Manual de Gestão do Programa Escola da Terra utiliza o termo Tempo-Universidade e tempo escola, porém no trabalho iremos utilizar o termo "tempo escola e tempo comunidade", para fidedignar a fala dos participantes do Programa. 
possibilitando a visualização da identidade cultural das escolas e a construção do currículo contextualizado para e com os alunos das classes multisseriadas (FREIRE, 1981).

A formação continuada dos educadores deve dialogar com um currículo que tome como referência e valorize as diferentes experiências, saberes, valores e especificidades culturais das populações do campo.

Os saberes de experiências cotidiana dos sujeitos, no diálogo com os conhecimentos selecionados pela escola propiciarão o avanço na construção e apropriação do conhecimento por parte dos educandos e nos educadores. O conhecimento deve ser constituídos por todos, sem exceção, professores, estudantes, pais e membros da comunidade, devem ser envolvidos na construção coletiva do currículo.

Quando pensamos nos sujeitos que estão presentes nas escolas e como esta instituição se relaciona coma realidade local, o currículo pode e deve ser construído pela identidade cultural presente no espaço, os conhecimentos que devem ser selecionados para a educação/escolarização dos sujeitos do campo, os quais contribuíram significativamente para o fortalecimento de suas identidades individuais e coletivas (ROCHA; HAGE, 2010).Logo, o diálogo entre as diferentes formas de conhecimento constituídos pela população do campofoiefetuada pela formação continuada dos professores no Programa Escola da Terra, como verificamos a seguir

Os formadores que foram escolhidos pela instituição formadora que no caso é a Universidade Federal do Pará, foram formadores excelentes que mostraram pra nós como a gente poderia estar trabalhando as áreas do conhecimento e de uma maneira bem diversificada saindo daquele tradicionalismo, do conteúdo pelo conteúdo, trabalhando o conteúdo de uma forma mais dinamizada (Tutora do Programa Escola da Terra, 2016).

Os cursos de formação continuada de professores críticos, reflexivos e transformadores tem sido a lógica legitimante de criação sobre propostas críticas na formação docente. Na medida em que os(as) militantes educadores(as) dos movimentos que chegam a esses cursos carregam radicalidades políticas, culturais e educativas, acumuladas nas lutas dos movimentos, eles passam a exigir dos cursos de formação o reconhecimento desses saberes, valores, concepções de mundo, de educação, como ponto de partida de sua formação (ARROYO, 2012).

$\mathrm{Na}$ fala acima, para a educação do campo, o currículo deve expressar as marcas culturais da população do campo. Neste sentido, as práticas educativas devem estar ancoradas a uma perspectiva 
de um currículo interdisciplinar, com posicionamento crítico uma vez que respeite as diferenças, sejam sociais e culturaisde cada contexto.

No Programa Escola da Terra a formação continuada respeitava a construção dos conteúdos, de acordo com a realidade dos educadores do campo, como veremos a seguir:

\begin{abstract}
Olha antes a gente, não tinha assim conhecimento, o que que a gente tinha, recebia um conteúdo uma matriz curricular da escola pólo, porque todas nós do campo, nós somos anexas a cidade né? a uma escola pólo, então a gente recebia um conteúdo programático e ia trabalhar em cima daquilo. Depois da formação no Programa Escola da Terra a gente só teve ganhos, na minha visão assim, porque tá ampliando, tá colocando a nossa realidade e acrescentando tudo aquilo que pra nós é interessante lá no nosso lugar, trabalhar sobre rios, trabalhar poluição, trabalhar o desmatamento, que na cidade a gente não trabalha o desmatamento, na cidade não tem rio entendeu? Então tudo isso tá ampliando, e até pra gente tá construindo a nossa matriz curricular, o nosso complexo temático, que a gente precisa dessas formações, então agende tá aprendendo é aqui nessas formações (Professora do Programa Escola da Terra, 2016).
\end{abstract}

Segundo Oliveira, França, Santos, (2011) os conteúdos trabalhados pelos docentes em sua ação educativa estão centrados nos planos estabelecidos pelas Secretarias de Educação que se organizam por meio da proposta de um currículo com base nacional e, portanto, pouco refletem a realidade das classes multisseriadas do campo.

Antes do Programa Escola da Terra, conforme depoimento da professora acima, os professores das classes multisseriadas de Bragança recebiam uma matriz curricular da escola pólo, pronto e definida, com um conteúdo que geralmente não atendia aos pressupostos da multissérie. Com a formação continuada os conteúdos foram construídos pelo coletivo de educadores nas próprias formações continuadas, e a medida que eles retornavam para suas comunidades experimentavam sua aplicabilidade com os alunos. No retorno da próxima formação ocorria o momento de socialização destas experiências, para inclusive nortear as ações do programa, atendendo assim as necessidades destes profissionais da educação.

Hage (2016) destaca que a alternativa mais utilizada para viabilizar o planejamento dos professores do campo, tem sido seguir as indicações do livro didático, sem atentar com clareza para as implicações curriculares resultantes dessa atitude, uma vez que esses materiais didáticos têm imposto a definição de um currículo deslocado da realidade e da cultura das populações do campo da Amazônia.

Em uma das observações durante a formação foi possível identificar a organização curricular que dá base para o planejamento dos professores na sala de aula numa lógica da construção dos currículos interdisciplinares e contextualizados. Abaixo apresenta-se a construção 
coletiva entre a coordenação, professores e tutores para organizarem a sistematização do planejamento docente no chão da escola.

a) Objeto de Estudo - Aquilo que se pretende estudar e que está dentro do campo de interesse e vida dos educandos: realidade, fato, fenômeno, situação, coisa, desnaturalização, etc.

b) Problemas de Estudo - Questões problemas sobre o objeto de estudo que permitam sua compreensão a partir da realidade que possibilitam articulação com as disciplinas, conhecimentos, numa compreensão numa interatividade com outras disciplinas afins.

c) Métodos de Estudo - Descrição das atividades a serem realizadas para promover a construção das respostas para cada problema, desencadeando assim a produção do conhecimento, destacando as duas etapas, Pesquisa-Descritiva da Realidade [Etapa 1: Levantamento de Dados] e Problematização e Análise dos Dados Levantados [Etapa 2: Realidade Descrita], observando os momentos de aulas teóricas nas duas etapas.

d) Conteúdos de Estudos e Interdisciplinares - Descrição dos conteúdos por área de conhecimento, observando as possibilidades de interatividade entre as disciplinas no desenvolvimento do processo de construção do conhecimento, focando atividades, problematização e conteúdo de estudo.

e) Produtos de Estudos e Avaliação - Ações e Materiais que representem o conhecimento produzido: textos, mapas, desenhos, performances artísticas, atos políticos, bem como os momentos de reflexão sobre o processo de construção do conhecimento, a partir do envolvimento do coletivo dos sujeitos participantes mediante a cada objeto de estudo, desenvolvido no cotidiano escolar.

De acordo com o formador entrevistadoesta estrutura curricular está amparada. "Na concepção dialética de mundo, nada existe com apenas um conceito, tudo parte da realidade que gera vários contextos". Esta fala nos apresenta que a organização do currículo contextualizado se fez presente no Programa Escola Terra, devido este pensar nas múltiplas dimensões, políticos, históricos, culturais, econômicos, ambiental e social em que os sujeitos estão constituídos.

Esta organização do trabalho pedagógico, que se constituiu como um indicativo curricular, foi baseada a partir da quinta formação que tratava sobre as linguagens matemática e representação da realidade, como uma forma de exercício para o planejamento no cotidiano da escola e a 
sistematização da matriz curricular por escolas polos, respeitando assim a complexidade cultural de cada instituição educativa.

Para Hage (2016), as escolas multisseriadas possuem uma identidade diferenciada pela “precarização do modelo urbano seriado de ensino". Por isso, torna-se necessária uma educação que comtemple a diversidade e heterogeneidade de sujeitos, ou seja, uma educação escolar multicultural e inclusiva. Educação que oportunize o diálogo e a convivência entre os diferentes sujeitos e culturas, visando superar a realidade de exclusão social e educacional que grupos sociais sofrem por fatores de etnia, gênero, classe, idade, entre outras.

Portanto, é preciso ter escolas no campo, garantido o direito público e subjetivo do sujeito, de estudar, construir conhecimento, a partir do seu lugar, da sua história, da memória das comunidades rurais, dos patrimônios materiais e imateriais, por isto a política da educação do campo, não deve se redimir para um projeto de educação, no meio rural amazônico, com uma perspectiva da nucleação, retirando os direitos dos alunos de estudar em suas comunidades. Freire (2011), nos diz que o empoderamento do povo está em reconhecer a sua identidade, a sua cultura, os seus valores, pois é isto que politiza o sujeito para a criticidade e reinvindicação dos seus direitos pela terra, pela água, pela floresta, etc.

A qualificação com os professores cursistas no Programa Escola da Terra, permitiu um processo de reflexão sobreas ações pedagógicas dos docentes com os alunos em turmas multisseriadas. Por isto, enfatiza-se a necessidade de uma formação continuada que atenda a realidade do campo, a construção de um currículo contextualizado e interdisciplinar, e, um planejamento que respeite a prática docente.

A formação continuada é importante pois o professor dialoga entre a discussão teórica e metodológica no Programa Escola da Terra com aquilo que se vivencia, em sua prática educativa, no seu cotidiano escolar. Isto só é possível devido o reconhecimento da realidade em que este sujeito-professor se encontra.

Para Freire (2011), toda prática educativa demanda a existência de sujeitos, um que, ensinando, aprende, outro que, aprendendo, ensina, daí o seu cunho do reconhecimento da existência de objetos, conteúdos a serem ensinados e aprendidos; ao qual envolve o uso métodos de técnicas, práticas, que implicam, em seus objetivos, sonhos, utopias, ideias. Logo, a formação continuada propicia a ação- reflexão- ação sobre aquilo que precisa ser superado com as questões problemas do cotidiano escolar. 
Neste sentido a formação continuada dos professores no Programa Escola da Terra apresenta inúmeras perspectiva de respeito pela valorização do homem e da mulher do campo, e que este precisa continuar enquanto uma política pública afirmativa, para redimensionar as metodologias, técnicas, redefinição de planejamento e práticas dos docentes em seu cotidiano escolar. Isto foi possível no Programa Escola da Terra, quando este propiciou durante as formações com os educadores o exercício dos princípios educativos freireanos e da educação do campo, que permitiram tecer a concepção do currículo contextualizado e interdisciplinar para e com os educadores do campo, nas classes multisseriadas do município de Bragança.

\section{CONSIDERAÇÕES FINAIS}

Sabe- se que a educação do campo perpassa por uma luta que vem se solidificando através dos vários e intensos debates acerca desta temática, pois ao povo do campo foi negado o acesso, avanço, reconhecimento e garantia a educação de qualidade. É importante frisar que nos últimos anos a sociedade aprendeu que o campo estar vivo e que seus sujeitos necessitam de uma dinâmica,social, política e cultural, que atenda a sua realidade entrelaçada aos seus valores, família, trabalho, modos de ser mulher, homem, criança, adolescente, jovem,adulto ou idoso.

Nesta lógica foi pertinente observar que o programa escola da terra faz parte de uma das ações do PRONACAMPO e obtém ações específicas relacionado a educação dos povos do campo e quilombolas, implantado no município de Bragança por meio da portaria 579, em 02 de julho de 2013.

No período de 2014 à 2016foram desenvolvidas no Programa Escola da Terra, sete formações continuadas para os professores que atuam com classes multisseriadas do campo, no tempo universidade e tempo escola, estas formações tiveram como objetivo fortalecer o desenvolvimento de propostas pedagógicas e metodológicas adequadas a comunidades atendidas.

Durante as formações continuadas com os educadores das classes multisseriadas no município de Bragança, observou-se a presença dos princípios educativos freireanos e do campo, que foram a base para a construção de currículos contextualizados e interdisciplinares nas escolas.

Os princípios educativos freireanos e do campo, como a pesquisa sócio antropológica, o levantamento da realidade na sala de aula e comunidade escolar, da problematização nas realidades e da visualização da identidade cultural das escolas e seus sujeitos, possibilitavam um movimento dialético nas formações pela perspectiva metodológica, no programa escola da terra, da pedagogia da alternância, do tempo escola e tempo comunidade. 
Esta articulação intrínseca entre a formação continuada dos educadores e a concepção do currículo no programa escola da terra estava baseada na concepção de um currículo contextualizado e interdisciplinar, que possibilitou aos educadores o exercício da desnaturalização da realidade, bem como o diálogo entre as diversas áreas do conhecimento embasados pelo cheiro, cor, sabor, mapa, horta, artesanato, dança, tudo aquilo que se constrói materialmente no chão da escola, a partir da sua realidade, porque o conhecimento não é somente de letras, ele pode acontecer por meio da partilha dos saberes e da diversidade de cada ser humano, foi perceptível que os professores saíram desta formação fortalecidos e permeados por uma vasta gama de experiências que certamente influenciara na sua prática educativa, isto foi visível na culminância das partilha dos saberes que os professores apresentaram.

A materialização deste currículo construído por este coletivo de educadores perpassaram pela análise do objeto de estudo, problemas de estudo, métodos de estudo, conteúdos de estudos e interdisciplinares, produtos de estudos e avaliação. Estes indicativos curriculares permitiram durante as formações no tempo escola e tempo comunidade, o planejamento dos docentes no cotidiano escolar.

Sabe-se que ainda se faz necessário continuar lutando por direito a uma escola que permita o empoderamento dos seus alunos e que o assegure na sua comunidade. Porém, precisamos acreditar que a educação e o profissionalismo, são um viés para essa transformação, e o Programa Escola da Terra é um grande exemplo a ser seguido, pois rompeu com paradigmas da alienação, exclusão e mostrou através do trabalho coletivo que a formação continuada de professores é capaz de transformar vidas.

\section{REFERÊNCIAS}

ARROYO, Miguel Gonzalez. Formação de Educadores do Campo. In: CALDART, RoseliSalet; (Org.). Dicionário da Educação do Campo. Rio de Janeiro, São Paulo: Escola Politécnica de Joaquim Venâncio, Expressão popular, 2012.

ARROYO, Miguel Gonzalez; CALDART, Roseli Salet; MOLINA, Mônica Castagna (Orgs.). Por uma educação do campo.5.ed. Petrópolis, RJ: Vozes, 2011.

BRASIL. Lei de Diretrizes e Bases da Educação9394/96. Disponível em: http://www.planalto.gov.br/ccivil_03/leis/L9394.htm. Acessado em 15 Fev. 2015

BRASIL. Lei no 9.394, de 20 de dezembro de 1996 (especialmente o Título VI, artigos nº 61 e 62 que estabelece a formação de professores). Legislação Brasileira sobre Educação. Brasília: Câmara dos Deputados, 2015.

BRASIL. Portaria n. 579 de 02 de julho de 2013. Que institui a Escola da Terra. Disponível em: pronacampo.mec.gov.br/images/pdf/manual_escola_terra.pdf. Acessado em 21 Fev. 2016. 
BRASIL. Portaria n. 86 de 01 de fevereiro de 2013. Institui o Programa Nacional de Educação do Campo - PRONACAMPO, e define suas diretrizes gerais. Disponível em: pronacampo.mec.gov.br/images/pdf/manual_escola_terra.pdf. Acessado em 15 mar. 2016.

CORDEIRO, Georgina N. Kalife. Educação superior do campo e a Pedagogia da Alternância: o diálogo no processo de formação de professores. In: JÚNIOR, Fernando Alves da Silva; FERNANDES, José Guilherme dos Santos. Interculturalidade e saberes: os diversos na contemporaneidade da Amazônia. 1 ed. Belém, PA: Paka- Tatu, 2015.

FREIRE, Pedagogia do Oprimido. 11. ed. Rio de Janeiro: Paz e Terra, 1987.

FREIRE, Paulo. Pedagogia da autonomia: saberes necessários à prática educativa São Paulo: Paz e Terra, 2011.

FREIRE, Paulo. Ação Cultural para liberdade. 5ª ed. Rio de Janeiro. Paz e terra, 1981.

HAGE, Salomão. Curso de aperfeiçoamento da escola da Terra. Disponível em:http://portal.mec.gov.br/ultimasnoticias/202-264937351/20650-curso-de-aperfeicoamento-reune-400-professores-paraenses. Acessado em 20 mar. 2016.

HAGE, Salomão Antônio Mufarrej. Transgressão do paradigma da (multi)seriação como referência para a construção da escola pública do campo. Disponível em: http://www.scielo.br/pdf/es/v35n129/0101-7330-es-35-129-01165.pdf. Acessado em 26 Jun. 2016.

MANUAL DE GESTÃO. Programa Escola da Terra, 2012. Disponível em: pronacampo.mec.gov.br/images/pdf/manual_escola_terra.pdf Acessado em 21 Fev. 2016.

OLIVEIRA, Ivanilde Apoluceno de; FRANÇA, Maria do Perpétuo Socorro G. S. A. de; SANTOS, Tânia R. Lobato (Orgs.). Educação em classes multisseriadas na Amazônia: singularidade, diversidade e heterogeneidade. Belém: EDUEPA, 2011.

ROCHA, Maria Isabel Antunes; HAGE, Salomão Mufarrej (Orgs.). Escola de direito: reinventando a escola multisseriada. Belo Horizonte: Autêntica Editora, 2010.

ROCHA, Maria Isabel Antunes; MARTINS, Aracy Alves. Educação do campo: desafios para formação de professores. 2. Ed. Belo Horizonte: Autêntica Editora, 2011.

\section{RESUMO}

Propõe-se analisar a formação continuada de professores do Programa Escola da Terra no município de Bragança, Amazônia Oriental. Observação participante e entrevistas semi- estruturadas e grupos focaisforam as técnicas de coleta de dados. O Programa Escola da Terra desenvolveu em Bragança formações continuadas para os professores das escolas do campo que atuam na multissérie.Sete formações se constituíram no regime de alternância no tempo escola e tempo comunidade, com base curricular via complexo temático. A formação continuada do Programa construiu comos professores um planejamento curricular embasado por conhecimentos interdisciplinares a partir das experiências dos sujeitos do campo, a valorização de sua realidade e de seus saberes.

PALAVRAS - CHAVE: FORMAÇÃO; MULTISSÉRIE; EDUCAÇÃO DO CAMPO;

\section{ABSTRACT}

It's purposed to analyze the continued formation of teachers from Program School of Earth in the municipality of Bragança, Oriental Amazonia. Participant observation, semi-structured interviews and focal groups were the technics to collect the data. The Program School of Earth developed in Bragança continued formation for teachers from country schools who work at multiseries. Seven formations were constitutedin rotationscheme at school time and community time, with curricular base via thematic complex. The continued formation of the Program built with the teachers a curricular planning based on interdisciplinary knowledge from experiences of country individuals, the valuing of their reality and their knowledge.

KEY-WORDS: FORMATION; MULTISERIES; FIELD EDUCATION; 